\title{
Omental Cyst Presenting as an Acute Abdomen in a Pediatric Patient: A Case Report
}

\author{
Hailu Alemu', Seifu Alemu², Melkamu Berhane $\mathbb{D}^{\prime}$ \\ 'Department of Pediatrics and Child Health, Jimma University, Jimma, Ethiopia; ${ }^{2}$ Department of Surgery, Jimma University, Jimma, Ethiopia \\ Correspondence: Hailu Alemu, Email hailuca24@gmail.com
}

\begin{abstract}
Background: Omental cysts are the rarest forms of intra-abdominal cystic lesions. They are usually asymptomatic but can also present as acute abdomen. The presentation is confusing in some cases, which may result in mismanagement, added costs, and trouble for the patient. A pre-operative diagnosis is challenging, especially in resource-limited settings, and requires a high level of suspicion and a cautious approach during emergency exploratory laparotomy to avoid complications.

Case Details: This is a 4 year old male child who presented with high grade fever, vomiting, and abdominal pain of 2 days duration. He was tachypneic, tachycardic, and had diffuse abdominal tenderness. Emergency laparotomy revealed a large cyst with hemorrhagic content. Complete removal of the cyst was done, and the patient was discharged after improvement on the third post-operative day. Conclusion: Omental cysts are rare in children and have varieties of presentations. Even though preoperative diagnosis is challenging, esspecially in resource-limited settings, clinicians should consider omental cysts in a child presenting with an acute abdomen. It is important for surgeons to consider omental cysts when carrying out emergency laparotomy for an unidentified abdominal condition.
\end{abstract}

Keywords: omentum, cyst, abdomen, acute

\section{Introduction}

Omental cysts are any cyst that is confined to the greater or lesser omentum, the most common site being the greater omentum. The incidence of mesenteric and omental cysts is closer to one in 20,000 among children, and it is even lower in infants. So far, only about 150 cases have been reported, of which only $25 \%$ have been detected in children less than 10 years of age. ${ }^{1,2}$

Omental cysts have uncertain etiologies; lymphangioma being the most commonly incriminated etiology. They have varieties of presentations based on their number, location, size, and content. They can also present with features of an acute abdomen due to bleeding into the cysts, torsion, or rupture of the cysts. ${ }^{3,4}$

Because of these diverse clinical presentations, pre-operative diagnosis is challenging, especially in resource-limited settings. If done by an experienced radiologist, ultrasound can reliably be used to diagnose abdominal cysts, whereas computed tomography (CT) scans and magnetic resonance imaging (MRI) provide more details about the extension and interior properties of these lesions. ${ }^{5}$

Since there is no medical therapy available, the only option of treatment is surgical removal; open surgical resection is preferred over laparoscopic excision to avoid spillage. ${ }^{6}$

Given the rarity of large omental cysts, we hereby report a case of a large omental cyst presenting as an acute abdomen in a 4 year old child.

\section{Case Details}

A 4 year old male child presented to our hospital with abdominal pain of 2 days duration, which was initially around the periumbilical area and later involved the whole abdomen. He had associated high grade fever, nausea, and vomiting of the same duration. On physical examination, he was in pain and he was tachycardic ( $\mathrm{PR}=144$ beats/minute), tachypneic $\left(\mathrm{RR}=54\right.$ breaths $/$ minute), and febrile (temperature $\left.=39.2^{\circ} \mathrm{C}\right)$. All the anthropometric indices were in the normal range. 
Additionally, he had a dry tongue and buccal mucosa, hypoactive bowel sounds, and diffuse tenderness all over the abdomen. Investigations revealed leukocytosis $(\mathrm{WBC}=20,080 / \mu \mathrm{L})$ and hematuria (blood $+4, \mathrm{RBC} 10-50 / \mathrm{hpf}$ ). Other cell lines were normal $\left(\mathrm{RBC}=4.1 \times 10^{6} / \mu \mathrm{L}\right.$, Hemoglobin $=11.1 \mathrm{~g} / \mathrm{dL}$, Platelet $\left.=334,000 / \mu \mathrm{L}\right)$. Preoperative imaging studies were not done because they are not available on an emergency basis.

With an initial impression of generalized peritonitis secondary to? He was rehydrated with normal saline, started on intravenous Ceftriaxone $500 \mathrm{mg}$ IV bid and Metronidazole $135 \mathrm{mg}$ IV tid, and a nasogastric tube was inserted for decompression. He then underwent emergency laparotomy, which revealed a large cystic mass with hemorrhagic content measuring around $15 \mathrm{cmX} 20 \mathrm{~cm}$, arising from the splenic flexure (Figures 1 and 2); there was only minimal reactive fluid in the general peritoneum. The cyst was carefully removed and the child had smooth post-operative days until his discharge on the third day.

\section{Discussion}

Intra-abdominal cysts in children can arise from the solid organs, retroperitoneum, mesentery, or omentum. Omental cysts are confined to the lesser or greater omentum, and they can be of variable size. The cysts can either be unilocular or multilocular and they may contain hemorrhagic, serous, chylous, or infected fluid. ${ }^{7-9}$ In our patient, it was huge, (most possibly the largest from the omentum so far), unilocular, and containing thin hemorrhagic fluid.

Presentation of omental cysts varies based on the size and site of the cyst. These cysts may be detected pre-operatively or intra-operatively incidentally when complicated with infection, torsion, or infarction in patients presenting with acute abdominal pain, abdominal distention, or ascites. ${ }^{4,7}$ The diagnosis of an omental cyst was made incidentally intra-operatively in our patient. Presentations with severe anemia, massive ascites, and teratomatous cyst were also reported, ${ }^{8}$ none of which was there in our patient. An accurate preoperative diagnosis of omental cysts is usually difficult and a correct preoperative diagnosis was reported in less than a quarter of the cases. ${ }^{7}$ Radiological imaging modalities are helpful in diagnosing omental cysts preoperatively but might be difficult to obtain right away in resource-limited settings. Like most of the cases, we did not diagnose an omental cyst as the cause of the acute abdomen preoperatively because we did not do any imaging test (it was not

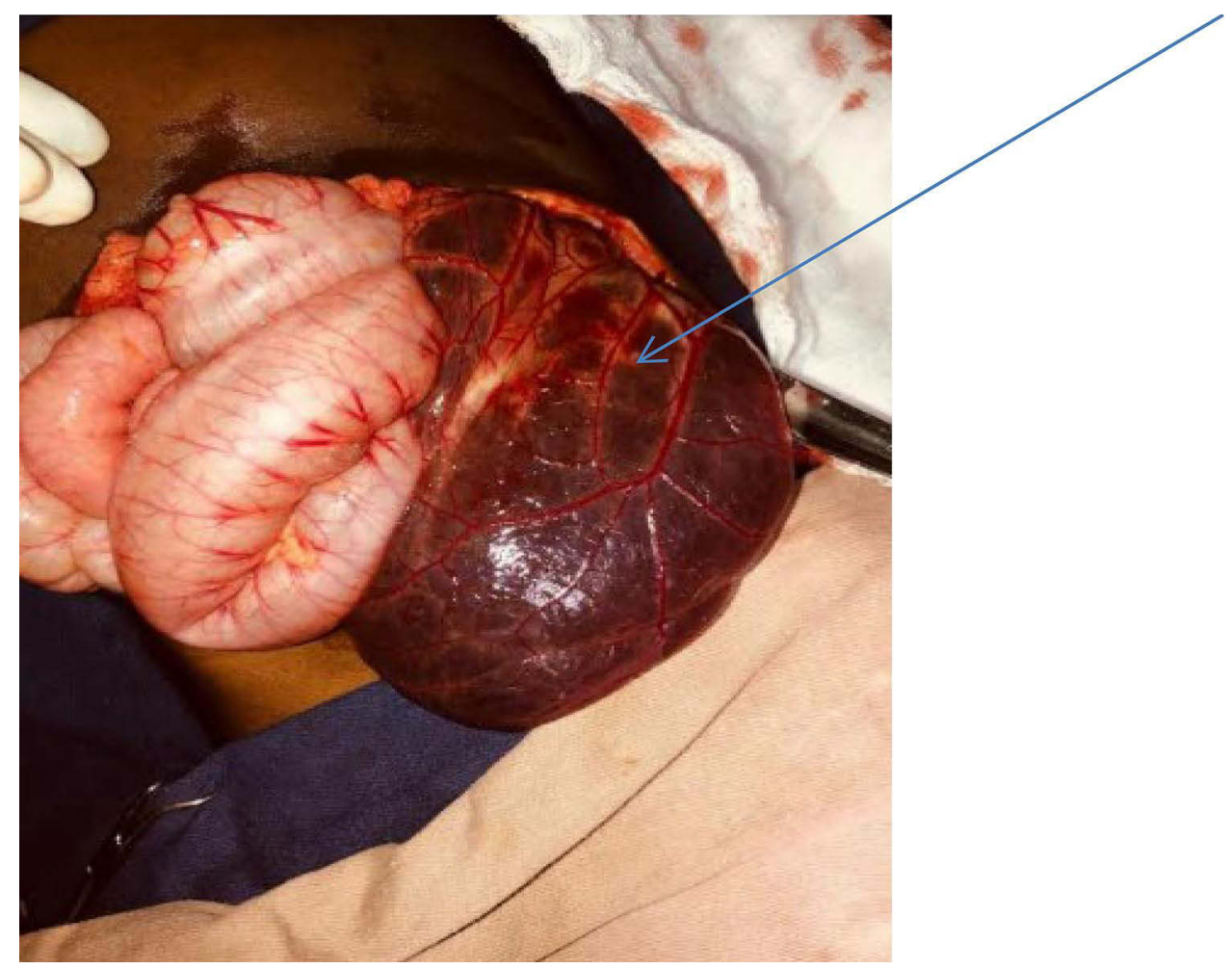

Figure I Cystic mass on the splenic flexure (arrow). 


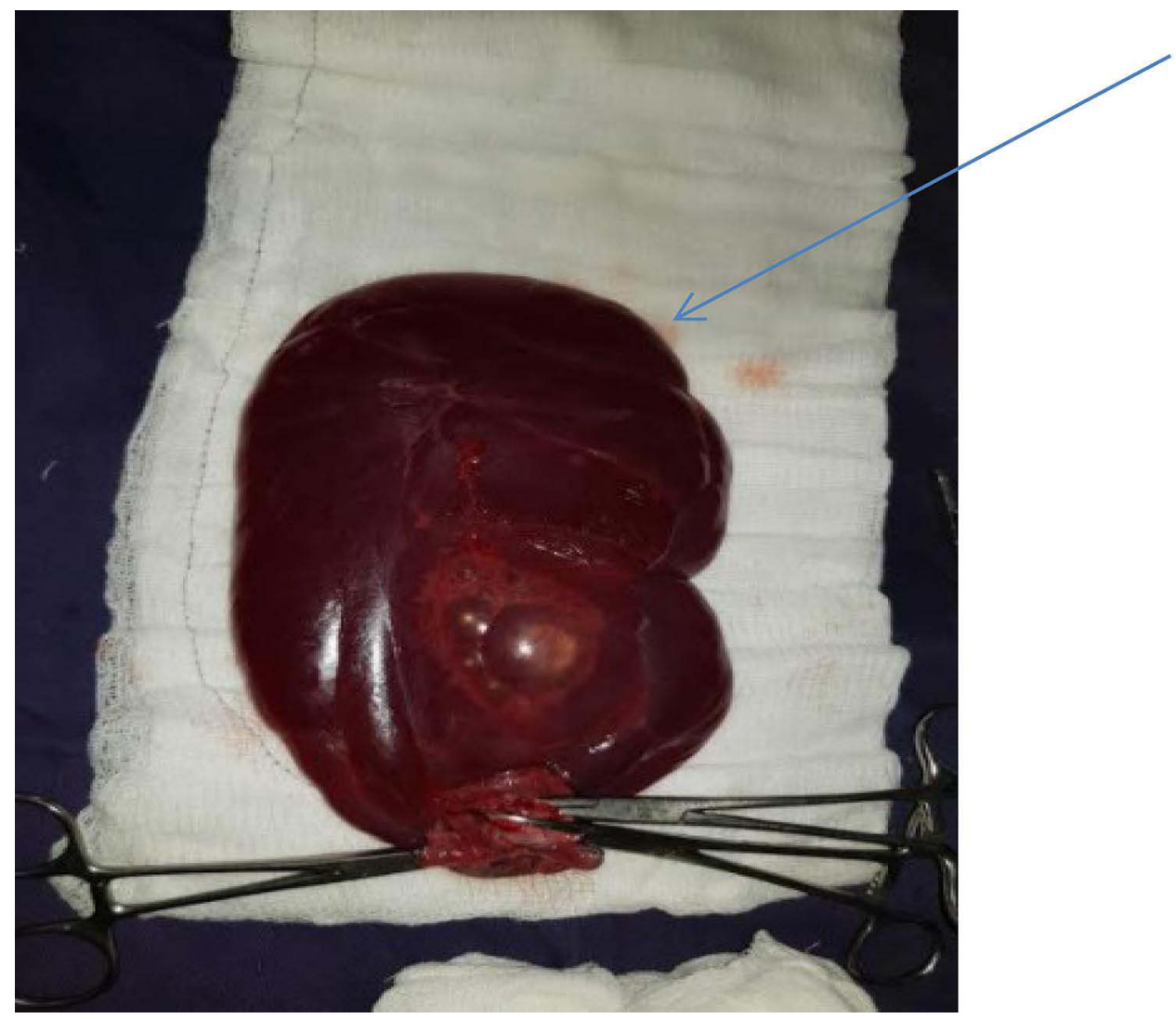

Figure 2 Cystic mass after resection (arrow).

possible to do these tests at the time of arrival, since it was not available) and we did not want to delay intervention while the child had obvious signs of peritonitis and hence the diagnosis of anomental cyst was made intra-operatively.

When the diagnosis is made pre-operatively, open surgical excision is preferred over laparoscopic excision in order to avoid the risk of rupture and spreading of the cyst contents. Besides, laparoscopic removal may be difficult in children who have relatively smaller space for portal placement and subsequent manipulations, especially in cases of large cysts. No matter the type of surgical intervention performed, total excision should be the goal in order to avoid recurrence. ${ }^{6,9}$ If total excision is not possible because of the size of the cyst or because of its location deep within the root of the mesentery, partial excision with marsupialization of the remaining cyst into the abdominal cavity is an option and approximately $10 \%$ of the patients require undergoing this form of therapy. If marsupialization is performed, the cyst lining should be sclerosed with $10 \%$ glucose solution, electrocautery, or tincture of iodine to minimize recurrence. ${ }^{9}$ In our case, after identifying the cyst, it was cautiously excised and removed without rupture.

Complications from surgery, either early or late, are uncommon. The main complication after surgical treatment is recurrence, which has been reported to occur in $9.5 \%$ of patients especially when resection is incomplete. Complications of the cyst include hemorrhage, torsion, infection, rupture, and symptoms related to pressure effects of the cystic mass on the adjacent structures. ${ }^{8}$ The child in the presented case had a large cyst with hemorrhagic content, resected without rupture, and he had no complications in the first 3 months of follow-up. But long-term complications like recurrence of the cyst needs additional follow-up. Even if he was given a follow-up appointment, he did not come back and, hence, we did not assess his conditions subsequently.

\section{Conclusion}

Omental cysts are rare in children and have varieties of presentations. Preoperative diagnosis is challenging, especially in resource-limited settings with limited access to pre-operative imaging modalities. Hence, it is wise for clinicians working 
in resource-limited settings, where emergency imaging is unavailable and emergency laparotomy needed for an acute abdomen for an identified cause. It will be wise to consider omental cysts as a possible differential diagnosis in these children presenting with features of acute abdomen, and care should be taken to avoid intra-operative complications like rupture and spillage of the cyst/s into the abdominal cavity.

\section{Ethical Consideration}

As this is a case report, institutional approval for publication was not required. However, the parents of the child have given us their written informed consent to publish the case and the images.

\section{Acknowledgments}

We would like to thank the parents for giving us their consent to report the case.

\section{Disclosure}

The authors declare that they have no conflicts of interest related to this work.

\section{References}

1. Kurtz R, Heimann T, Holt J, Beck A. Mesenteric and retroperitoneal cysts. Ann Surg. 1986;203:109-112. doi:10.1097/00000658-198601000-00017

2. Motie MR, Asadi M. Large omental cyst: a case report and review of the literature. Acta Med Iran. 2011;4:690-693.

3. Gupta S. Omental cyst: an atypical presentation in a child masquerading tubercular ascites with severe acute malnutrition and sickle cell disease. $J$ Surg Surg Res. 2017;3(1):006-9.

4. Sayeed M, Benzamin M, Akter S, Mazumder MW, Karim AS, Dey BP. Omental cyst - rare cause of abdominal pain in a 7-year-old child: a case report. Port J Gastroenterol. 2021;28(3):202-206. doi:10.1159/000510022

5. Chateil J-F, Brun M, Vergnes P, Andrieu De Lewis P, Pérel Y, Diard F. Abdominal cystic lymphangiomas in children: presurgical evaluation with imaging. Eur J Pediatr Surg. 2002;12(1):13-18. doi:10.1055/s-2002-25090

6. Tan JJ-Y, Tan -K-K, Chew S-P. Mesenteric cysts: an institution experience over 14 years and review of literature. World J Surg. 2009;33(9):19611965. doi:10.1007/s00268-009-0133-0

7. Sag S, Okatan BK, Metin N, Rare A. Cause of acute abdomen in a child: infected mesenteric cyst. Dicle Tip Derg. 2019;881-883. doi:10.5798/ dicletip.661423

8. SarperErikci V, Abay E, Köylüoğlu G. Omental cysts mimicking acute abdomen in a 3-year-old girl. Clin Diagn Pathol. 2017;1(2). Available from: http://oatext.com/Omental-cysts-mimick $\% \mathrm{C} 4 \% \mathrm{~B} 1$ ng-acute-abdomen- $\% \mathrm{C} 4 \% \mathrm{~B} 1 \mathrm{n}-\mathrm{A}-3$-year-old-g\%C4\%B1rl.php.

9. Antao B, Tan J, Quinn F. Laparoscopic excision of large intra-abdominal cysts in children: needle hitch technique. Case Rep Med. 2015;2015:1-5. doi: $10.1155 / 2015 / 937191$

\section{Publish your work in this journal}

The International Medical Case Reports Journal is an international, peer-reviewed open-access journal publishing original case reports from all medical specialties. Previously unpublished medical posters are also accepted relating to any area of clinical or preclinical science. Submissions should not normally exceed 2,000 words or 4 published pages including figures, diagrams and references. The manuscript management system is completely online and includes a very quick and fair peer-review system, which is all easy to use. Visit http://www.dovepress.com/testimonials. php to read real quotes from published authors.

Submit your manuscript here: https://www.dovepress.com/international-medical-case-reports-journal-journal 